\title{
The prospects for secondary processing of tailings remained after the beneficiation of fluorite ores of Primorye Krai using a highly selective combination of reagents
}

\author{
Lidiya Kienko $^{1 *}$ and Olga Voronova ${ }^{1}$ \\ ${ }^{1}$ Mining Institute of Far eastern branch of Russian Academy of Sciences, Khabarovsk, Russia.
}

\begin{abstract}
The study of the composition and preparability of two samples of tailings dumped at the Yaroslavl Mining Company revealed the following contents: $\mathrm{CaF}_{2}-15.2$ and $20.7 \%, \mathrm{CaCO}_{3}-13.3$ and $10.2 \%$, and $\mathrm{Zn}-0.49$ and $0.38 \%$. The volume of the stockpiled wastes is estimated at 30 million tons. The need for fine material grinding at the stage of preparation for flotation was shown, and the efficient fluorite concentration was possible with technical solutions found. The determined optimal parameters of the flotation acid-base condition provided neutralization of the negative influence of salts and slimes left by the previous processing cycle. It has been established that a mixture of ammonium and lignosulfonates was effective as a modifier. The extraction of sample 1 yielded $52 \%$ of fluorite extraction to the concentrates with $92.2-92.8 \%$ fluorite content, and more than $69 \%$ when beneficiating the sample 2 . Upgrading of the concentrate quality is only possible through transferring to flotation tails of the most contaminated fluorite grains impregnated with silicate minerals, but this is followed by a significant extraction reduction. The concentration of sphalerite to a separate product occurs with low effectiveness. The inclusion of sulfide flotation in the circuit head can improve the fluorite cycle efficiency: extraction of $\mathrm{CaF}_{2}$ to the concentrates of FF-92 brand may reach $70 \%$. Keywords: mineral mining and processing wastes, fine dissemination, fluorite, secondary processing, flotation, selectivity, modifiers.
\end{abstract}

\section{Introduction}

In the midst of a significant reduction in the ore reserves, which are primary sources for the production of fluorite concentrates and progressive decline in their quality, the prospects for stable supply of raw materials to the aluminum industry and other industries using fluorinated compounds might be associated with the involvement of mining and processing plants in the processing of residue waste. The stocks of accumulated waste processing mineral raw materials of production are estimated at a number of enterprises in tens of millions of tons $[1,2]$. Thus, the volume of tailings of fluorite ore concentration of the

* Corresponding author: kienkola@,rambler.ru 
Yaroslavl Mining Company (YAGRK), based on the processing of the ore of the Voznesensky ore district of Primorsky Krai, is estimated at more than 30 million tons. The content of fluorite in them varies between $13-23 \%$. The average value of the carbonate module $\left(M_{\kappa}=\alpha_{\mathrm{CaF}_{2}} / \alpha_{\mathrm{CaCO}_{3}}\right)$, which largely determines the preparability of raw materials, is 1.4-1.6.

The ores of the Voznesenskiy fluorite district are quite complex ones due to a number of reasons $[3,4]$. One of the main reasons is very close (up to emulsion) mutual germination of mineral phases, which dictates the need for fine grinding. The availability of two calcium-containing components presupposes problems in the selection of minerals in the flotation beneficiation of raw materials. In addition, flotation mica, topaz is present in ores; in separate massifs, the increased content of carbonaceous and clayey components is observed.

\section{Materials and Methods of the Research}

In the two samples of residue raw materials selected for research, which are the tailings of the primary processing of ores, fluorite is found mainly in either difficult to open splices or in slimes, which further complicates the concentration thereof in a separate product. The processing flow scheme for such a product should include simultaneous operations aimed at opening fluorite with the removal of films of secondary formations and stabilizing the dispersed pulp composition, taking into account the presence of sludge of various nature. The following main components were determined by chemical analysis: $\mathrm{CaF}_{2}-15.2-20.7$ $\%, \mathrm{CaCO}_{3}$, respectively, $13.35-10.2 \%, \mathrm{SiO}_{2}-30.85-32.2 \%, \mathrm{Zn}-0.49-0.38 \%$. For the successful development of techniques for fluorite separation with obtaining branded fluorite concentrates, it is necessary to estimate the beneficiation of each sample taking into account the main determining factors:

1. The granulometric characteristics of the sample, the peculiarities of the mutual germination of mineral components, the necessary preparation of the material by size.

2. Physico-chemical parameters of the water-mineral suspension providing a minimal effect on the process of residues of primary beneficiation reagents and secondary surface formations $[5,6]$.

3. The existing practice of flotation separation of finely dispersed mineral phases with similar adsorption characteristics.

4. Identifying the most promising areas of research and searching for new technological solutions that provide the required level of breeding.

The research of the granulometric composition of the samples has shown that the selected tailings material in the original form contains significantly fewer grains of the size controlled by the concentrator of the YAGRK $(-0.044 \mathrm{~mm})$ than the current waste of processing of fluorite ores (51-53\% against 70-85\%), obviously, with the natural processes of segregation occurring in the tailings pond. Therefore, the feed was subjected to grinding in a ball mill for 20 minutes, which allowed obtaining a material close in size to the composition of the milled ore during primary processing thereof.

The preliminary research data on the possibility of extracting fluorite from the raw materials prepared in this way are provided in Table 1 . The obtained results indicate some features of flotation beneficiation of secondary raw materials.

Calcite content in dedicated concentrates, particularly in experiments using developed technology based on the use as a modifier of mixes with ammonium fluoride [7], can be estimated as extremely low, indicating the process selectivity. At the same time, the content of fluorite in the concentrates does not reach the high-grade level (not more than 93.28\% $\mathrm{CaF}_{2}$ ). When beneficiating ore material with ammonium fluoride compositions and dosage 
of lignosulfonate, such low contents of calcite corresponded to the production of high purity concentrates $\left(95 \% \mathrm{CaF}_{2}\right.$ and more).

Table 1. The results of the experiments to extract fluorite from tailing samples using the standard technology of the YAGRK ore-processing plant.

\begin{tabular}{|c|c|c|c|c|c|}
\hline \multirow{2}{*}{$\begin{array}{c}\text { Experi } \\
\text { ment }\end{array}$} & \multirow{2}{*}{ Product } & \multicolumn{2}{|c|}{ Content, \% } & \multirow{2}{*}{$\begin{array}{l}\text { Extraction } \\
\text { of } \mathrm{CaF}_{2}, \%\end{array}$} & \multirow{2}{*}{ Note } \\
\hline & & $\mathrm{CaF}_{2}$ & $\mathrm{CaCO}_{3}$ & & \\
\hline \multirow{5}{*}{1} & Concentrate & 92.11 & 0.96 & 37.65 & \multirow{5}{*}{$\begin{array}{c}\text { Sample } 1 \\
\text { NaF-1,000 g/t } \\
\text { Ic }=83.7\end{array}$} \\
\hline & Intermediate & & & 49.60 & \\
\hline & feedstock 1-6 & 20.40 & 25.23 & & \\
\hline & Tailings & 3.34 & 6.87 & 12.75 & \\
\hline & Flotation feed & 15.02 & 13.21 & 100 & \\
\hline \multirow{5}{*}{2} & Concentrate & 91.05 & 1.04 & 49.92 & \multirow{5}{*}{$\begin{array}{c}\text { Sample No.2 } \\
\mathrm{NaF}-900 \mathrm{~g} / \mathrm{t} \\
\mathrm{Ic}=42.67\end{array}$} \\
\hline & Intermediate & & & 44.29 & \\
\hline & feedstock $1-5$ & 21.58 & 19.67 & & \\
\hline & Tailings & 2.65 & 3.59 & 5.80 & \\
\hline & Flotation feed & 20.89 & 10.19 & 100 & \\
\hline \multirow{5}{*}{3} & Concentrate & 93.28 & 0.59 & 49.21 & \multirow{5}{*}{$\begin{array}{c}\text { Sample 1 } \\
\mathrm{NH}_{4} \mathrm{~F}+\mathrm{LS}- \\
700+150 \mathrm{~g} / \mathrm{t} \\
\mathrm{Ic}=136.7\end{array}$} \\
\hline & Intermediate & & & 42.65 & \\
\hline & feedstock 1-6 & 19.89 & 23.67 & & \\
\hline & Tailings & 2.05 & 8.89 & 8.14 & \\
\hline & Ore & 15.05 & 13.00 & 100 & \\
\hline \multirow{5}{*}{4} & Concentrate & 93.27 & 0.49 & 55.22 & \multirow{5}{*}{$\begin{array}{c}\text { Sample No.2 } \\
\mathrm{NH}_{4} \mathrm{~F}+ \\
\text { lignosulphonate- } \\
600+100 \mathrm{~g} / \mathrm{t} \\
\mathrm{Ic}=92.03\end{array}$} \\
\hline & Intermediate & & & 39.7 & \\
\hline & feedstock 1-6 & 20.67 & 20.49 & & \\
\hline & Tailings & 2.22 & 3.95 & 5.08 & \\
\hline & Ore & 20.83 & 10.14 & 100 & \\
\hline
\end{tabular}

The extraction of fluorite by technology with the use of a new composition of modifiers in open-type experiments amounted to $49.8-55.22 \%$. The use of the traditional regime provides a much lower performance. Selective separation of fluorite and calcite when replacing sodium fluoride with ammonium fluoride mix with lignosulfonates increases due to several factors. The fluorine content in the $\mathrm{NH}_{4} \mathrm{~F}$ molecule is significantly higher, compared with $\mathrm{NaF}$ (51.3 and $45.2 \%$, respectively). Dissociation of the molecule $\mathrm{NH}_{4} \mathrm{~F}$ is much more active than that of the NaF molecule, because of the highest solubility of ammonium fluoride. In addition, in connection with the use of sodium carbonate in the flotation process as a medium regulator, sodium $\mathrm{Na}+$ cations are already present in the pulp at the time of filing of sodium fluoride, somewhat shifting the dissociation process of $\mathrm{NaF}$ towards the slowing down. Lignosulfonates have a depressant effect on a wide range of minerals, including calcite and silicates.

Mineralogical viewing revealed that, despite the finish grinding, which provides the content of the $-0.044 \mathrm{~mm}$ class for about $90 \%$, fluorite particles are marked with minute sprouts and primings of other minerals, such as quartz, tourmaline, garnets, mica, etc. Figure 1 shows photographs of fluorite concentrate made with the JEOL scanning electron microscope, equipped with the JCM-6000 PLUS energy dispersive analyzer.

Even with a low degree of magnification, the images clearly show that pure fluorite grains in the isolated concentrates are practically absent. Insufficient disclosure of mineral components, as well as the presence of various emulsion impregnations in fluorite grains, is the most probable causes, which do not allow obtaining high purity concentrates. During almost the entire period of operation, before stopping for reconstruction, the Yaroslavl Mining Company produced concentrates of FF-90 grade, and of the FF-92 grade in fewer amounts, containing 90 and $92 \% \mathrm{CaF}_{2}$, respectively. 

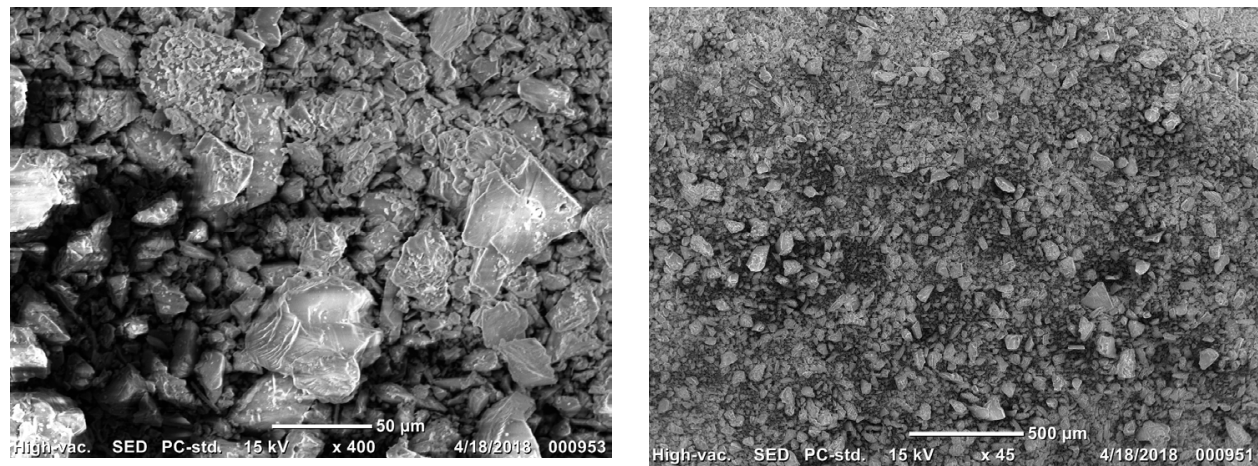

Fig. 1 Fluorite concentrate in varying degrees of magnification.

At the present time, in connection with the increased demand for high-grade concentrates, both on the domestic and world markets, the issue of improving their quality has risen sharply $[8,9]$. To derive products that in their composition correspond to the FF-95, FF-97 grades with satisfactory extraction indices, from such low-quality raw materials is almost impossible. However, under the conditions of the planned conversion of cryolite production technologies, the content of the consumer in $\mathrm{CaF} 2$ concentrates below $93-94 \%$ is not satisfactory. In the cycle of experiments with a further reduction in the size of the boundary grain and the identification of the effect of fineness of grinding on the flotation indices, it has been established that the optimum grinding size corresponds to a content of the -0.044 $\mathrm{mm}$ class of not less than $95-97 \%$. Further increase in the fineness of grinding leads to a decrease in technological indices, which is caused by increasing slurry fractions volumes [10-12].

\section{Results and Discussion}

Exploring the possibilities of stable flotation of residue tailings and obtaining the highest quality of fluorite concentrates from them requires detailed analysis of the selectivity dependencies of mineral separation on the complex of parameters affecting the process [13, 14]. One of the main factors determining the efficiency of interaction of ore components with reagents in the flotation medium is the neutralization of the effect on the process of residues of the primary beneficiation reagents formed during storage of the material in the tailings pond of the films and their slime-like chips that have arisen during the grinding process. Achieving the optimal acid-base composition of the liquid phase of the pulp can significantly reduce the activity of the chemical and physico-chemical interaction of the flotation pulp components. Fig. 2 presents the results of studies of the influence of the dosage of the medium regulator on the flotation results.

With an increase in the consumption of calcined soda, there is a steady increase in the extraction of fluorite into the concentrate during the flotation of both samples. With the increased dosage of $\mathrm{Na}_{2} \mathrm{CO}_{3}$ from 1 to $2.5-3.5 \mathrm{~kg} / \mathrm{ton}$, the quality of concentrates increases: the content of $\mathrm{CaF}_{2}$ increases from $89.61-92.45 \%$ to $93.67-93.96 \%$. The selectivity index of the separation of fluorite and calcite also increases when each of the two samples is dressed. Higher consumption of the alkaline regulator leads to a decrease in the selective characteristics of flotation; the extraction of fluorite stably increases.

Further studies to optimize the performance parameters for the purpose of extracting concentrates of higher grades were carried out in various directions: varying the composition and consumption of the modifiers, increasing the number of recleaning operations and the corresponding concentrations of reagents in them. In addition, the expediency of sulfides inclusion in the flotation head with the utilization of a fine flotation 
mixture of pyrite, pyrrhotite and sphalerite was investigated. The possibility of selecting a sulfide product and isolating sphalerite into a separate concentrate was also studied. The results of the experiments are shown in Table 2.


Flotation indices

Consumption of $\mathrm{Na}_{2} \mathrm{CO}_{3}, \mathrm{~kg} / \mathrm{t}$

Fig. 2. Dependence of fluorite flotation indices from the residue raw material of sample $1(a)$ and 2 (b) on the consumption of calcined soda: 1 - the content of $\mathrm{CaF}_{2}$ in the concentrate; 2 - extraction of fluorite into concentrate; 3 - index of selectivity of separation of fluorite and calcite $\left(I_{C}=\varepsilon_{\mathrm{CaF}_{2}} / \varepsilon_{\mathrm{CaCO}_{3}}\right)$; 4 - concentrate output.

Table 2. The results of research on the selection of the technological regime of fluorite flotation from tails of sample No. 2

\begin{tabular}{|c|c|c|c|c|c|c|}
\hline \multirow[b]{2}{*}{$\begin{array}{l}\text { Exper } \\
\text { iment }\end{array}$} & \multirow[b]{2}{*}{ Product } & \multirow[b]{2}{*}{$\begin{array}{c}\text { Output } \\
\%\end{array}$} & \multicolumn{2}{|c|}{ Content, \% } & \multirow{2}{*}{$\begin{array}{c}\text { Extrac } \\
\text { tion } \\
\mathrm{CaF}_{2}, \%\end{array}$} & \multirow{2}{*}{$\begin{array}{c}\text { Consumption } \\
\mathrm{NaF}+\mathrm{NH}_{4} \mathrm{~F}+\mathrm{LS} \\
(\text { bas.fl./recl), g/t }\end{array}$} \\
\hline & & & $\mathrm{CaF}_{2}$ & $\begin{array}{c}\mathrm{CaCO}_{3} / \\
\mathrm{SiO}_{2}\end{array}$ & & \\
\hline 26 & Concentrate & 15.36 & 92.21 & $1.48 / 2.74$ & 67.93 & $0+500+100$ \\
\hline 27 & Concentrate & 15.23 & 92.80 & $1.18 / 2.4$ & 67.86 & $0+500+100$ \\
\hline 28 & Concentrate & 14.77 & 92.82 & $0.79 / 2.48$ & 65.28 & $300+300+100$ \\
\hline 30 & Concentrate & 12.33 & 93.27 & $0.4 / 2.339$ & 55.22 & $0+600+100$ \\
\hline 31 & Concentrate & $11: 73$ & 93.46 & $0.39 / 2.33$ & 52.95 & $200+400+100$ \\
\hline 32 & Concentrate & 13.48 & 93.76 & $1.08 / 2.29$ & 60.88 & $\begin{array}{r}0+400+100 / 100+20 \\
(1-2 \text { recl. })\end{array}$ \\
\hline 33 & Concentrate & 8.94 & 95.07 & $0.4 / 1.87$ & 40.71 & $\begin{array}{r}0+600+100 / 100+20 \\
(1-3 \text { recl. })\end{array}$ \\
\hline \multirow{2}{*}{29} & \multicolumn{5}{|c|}{ Collective sulphide flotation in the head of the process } & $0+500+100 / 100+20$ \\
\hline & Concentrate & 16.06 & 92.21 & $1.68 / 2.68$ & 70.48 & $(1-2$ recl. $)$ \\
\hline
\end{tabular}

Note. In experiments 26, 28, 30, 31 - six, in the experiments 27, 29, 32, 33 - seven recleanings of the foam product;

The maximum extraction of fluorite into concentrates with a $\mathrm{CaF}_{2}$ content of over $93 \%$ was $60.88 \%$. The modifier was dosed both in the main flotation and in the recleaning. The increase in the costs of the modifier and the number of its supply points for the purpose of a more intensive concentration of fluorite made it possible to isolate the concentrate containing $95.07 \%$ of $\mathrm{CaF} 2$, however, its recovery has sharply decreased.

Silicon dioxide is a harmful impurity in fluorite concentrates, which has a negative 
effect on the process of their chemical processing, limited by GOSTs and technical conditions. Chemical analyzes revealed that the concentrates with a $\mathrm{CaF} 2$ content of 92.21$92.80 \%$, contain $2.74-2.40 \%$ of $\mathrm{SiO}_{2}$. As the concentration of $\mathrm{CaF} 2$ in the concentrates increases, the content of silica also decreases by $0.3-0.4 \%$. The obtained results testify to the compliance of $\mathrm{SiO} 2$ contents with GOST requirements for fluorite concentrates of FF92A and FF-92B grades. It should also be noted that the minerals carrying silicon dioxide in the concentrates are mainly micas and amphiboles. They lack free silica.

Flotation of fluorite according to the scheme with the preliminary extraction of sulphides (experiment 29) was not accompanied by an increase in the quality of fluorite concentrate, despite a general decrease in flotation sludge. However, the extraction of fluorite into a concentrate containing $92.21 \% \mathrm{CaF} 2$ was more than $70 \%$, which allows considering this variant of the technology as quite a promising one.

In periods of its stable work, in addition to processing fluorite ores and releasing fluorite concentrate, the YAGRK processing plant periodically processed zinc-fluorite raw materials. Flotation tailings were stored in the common tailings pond [15]. The possibility of concentrating sphalerite from residue tailings was studied according to the scheme in Fig. 3. Initially, collective sulphide flotation was carried out in a slightly alkaline medium created by calcined soda, and later - the concentration of sphalerite in a highly alkaline medium with a dosage of calcium hydroxide.

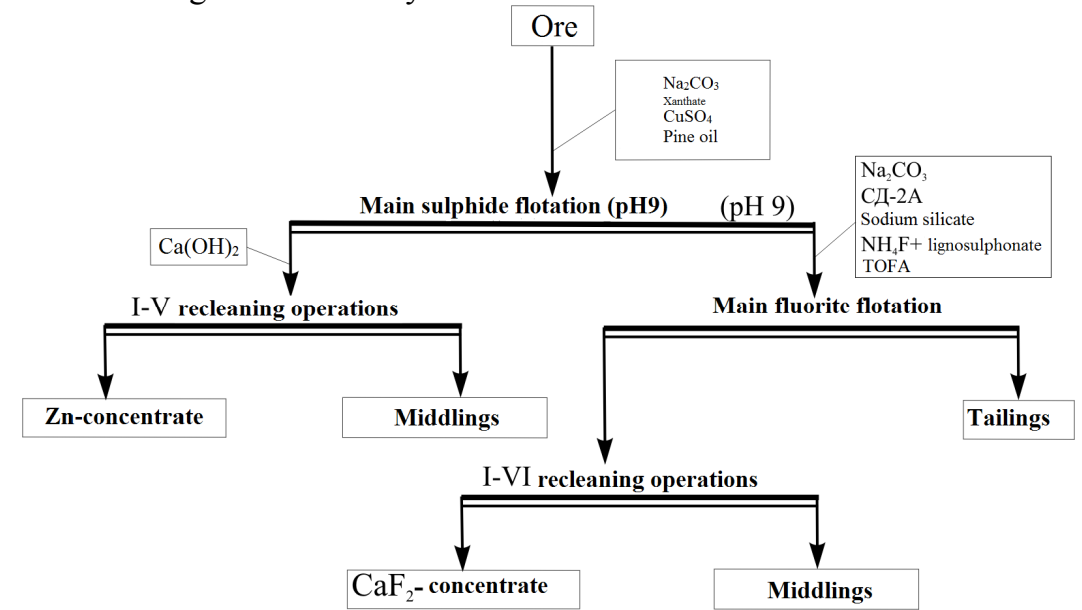

Fig. 3. Scheme for beneficiation of residue tailings with the preliminary extraction of sulphides.

The results of the research showed that beneficiation according to the scheme with the complex extraction of sphalerite and fluorite from the sample of residue tailings No. 1 allows obtaining zinc and fluorite concentrates. At the same time, zinc flotation is inefficient, which is predetermined by the low content of sphalerite in the feedstock. Extraction of zinc into a concentrate with a content of $42.11 \%$ was $38.84 \%$, and the extraction of fluorite in a concentrate containing $\mathrm{CaF}_{2}-92.98 \%-50.01 \%$. When beneficiating the sample No. 2, it was possible to isolate only a low-quality zinc product with a zinc content of $33 \%$. The feasibility of beneficiating residue raw materials in accordance with a scheme that includes a sulfide cycle can be finally assessed by economic calculations, as well as further studies on semi-industrial equipment with a continuous flotation cycle on a full scheme.

\section{Conclusions}

The composition and preparability of two samples of residue tailings of the Yaroslavl Mining Company, selected from the tailing dump of the enterprise, were studied. It was 
established that the content of fluorite in them is $15.2-20.7 \%$; zinc, represented by sphalerite - 0.49-0.38\%; calcite $13.35-10.2 \%$.

The mineralogical analysis found that almost all the fluorite grains are permeated with the finest sprouts and adherents of other minerals. Increasing the fineness of grinding does not allow achieving a significant increase in the degree of fluorite isolation.

The technology of flotation of fluorite from the residue tailings of the presented samples is proved and proposed, using ammonium fluoride-based modifiers. An effective regimen providing a decrease in the activity of the reagents used at the primary processing stage and secondary coatings was proposed.

Fluorite concentrates obtained by direct flotation in the open cycle contain 92.21$93.76 \% \mathrm{CaF}_{2}$. The extraction of fluorite with a content of $92 \%$ of $\mathrm{CaF}_{2}$ may be more than $52.54 \%$ for sample No. 1, and up to $67.86-69.49 \%$ for sample No. 2. The preparation of concentrates of higher purity is a complex task, which is due to the presence of inclusions in the fluorite grains. When the content in CaF2 concentrates increases to $93.28-93.76 \%$, the extraction in samples 1 and 2 decreases, respectively, by 3-6.5\%. The extraction of fluorite into a high-grade concentrate containing more than $95 \% \mathrm{CaF} 2$, was $40.71 \%$.

Beneficiation according to the scheme with the preliminary flotation of sulphides allows to increase the extraction of fluorite up to $70.17 \%$ with the content of $\mathrm{CaF}_{2}$ in the concentrate of $92.86 \%$. In this case, the concentration of zinc in a separate product passes with low efficiency.

\section{References}

1. N. I. Grekhnev, I. Yu. Rasskazov. Tich. geologiya journal, 35, No. 2, 107 (2016).

2. V. A Chanturiya., L. A Vaysberg., A. P. Kozlov. Obogashch. rud, 2, 3 (2014).

3. L. A Kiyenko, L. A Samatova. O. V.Voronova. Gorn. zhurnal, 12, 63 (2013).

4. V.Z. Schestovets, N. V. Egorov, V.E. Pavlov, L.V. Krylova. Gorn. zhurnal, 9, 26 (2000).

5. O. S. Bogdanov, Teoriya i tekhnologiya flotatsii rud. [Theory and technology of ore flotation.] 364 (M.: Nedra, 1990).

6. Gao Zhiyong, Bai Ding, Sun Wei, Cao Xuefeng, Hu Yuehua. Minerals Engineering, 72, 23 (2015).

7. L.A. Kienko, O. V. Voronova, Patent No. 2646268 Sposob obogashcheniya karbonatnoflyuoritovykh rud [Method for beneficiation of carbonate-fluorite ores]

8. Y. J. Li, F. Y. Sun, Y. Zhou, L. Zeng. Journal of Spectroscopy, 2015 (2015).

9. A. V. Fat'yanov, L. G. Nikitina, S. A. Shcheglova, O. L. Gorn. Zhurnal, 3, 82 (2011).

10. V.I. Klassen, D. I. Nedogorov, I. Kh. Deberdeyev, Shlamy vo flotatsionnom protsesse [Sludge in the flotation process] 160 (M.: Nedra, 1969).

11. L.A. Kienko, O. V. Voronova. Fiz. Techn. Probl. Razr. Polezn. Iskopaemykh, 1, 176 (2014).

12. Y. Yu, L. Ma, M. Cao, Q. Liu. Minerals Engineering, 114, 26 (2017).

13. F. Hernainz, M. Calero. Chemical Engineering and Processing, 40, 269 (2001).

14. S.A. Kondratyev, N. P. Moshkin. Phis. Techn. Probl. Razr. Polezn. Iskopaemykh, 4, 150 (2014).

15. L.A. Kienko, O. V.Voronova. Gorn.. zhurnal 2, 68 (2015). 